\title{
Predictors of overall survival in metastatic castration-resistant prostate cancer patients receiving $\left[{ }^{177} \mathrm{Lu}\right] \mathrm{Lu}-\mathrm{PSMA}-617$ radioligand therapy
}

\author{
Hojjat Ahmadzadehfar ${ }^{1, *}$, Stephan Schlolaut ${ }^{1, *}$, Rolf Fimmers ${ }^{2}$, Anna Yordanova ${ }^{1}$, \\ Stefan Hirzebruch ${ }^{1}$, Carl Schlenkhoff ${ }^{1}$, Florian C. Gaertner ${ }^{1}$, Zool Hilmi Awang ${ }^{1}$, \\ Stefan Hauser ${ }^{3}$ and Markus Essler ${ }^{1}$ \\ ${ }^{1}$ Department of Nuclear Medicine, University Hospital Bonn, Bonn, Germany \\ ${ }^{2}$ Institute for Medical Biometry, Informatics and Epidemiology, University of Bonn, Germany \\ ${ }^{3}$ Department of Urology, University Hospital Bonn, Bonn, Germany \\ *These authors contributed equally to this work
}

Correspondence to: Hojjat Ahmadzadehfar, email: hojjat.ahmadzadehfar@ukb.uni-bonn.de

Keywords: ${ }^{177} \mathrm{Lu}$, overall survival, PSMA, radioligand therapy, prostate cancer

Received: August 25, 2017 Accepted: October 04, $2017 \quad$ Published: October 07, 2017

Copyright: Ahmadzadehfar et al. This is an open-access article distributed under the terms of the Creative Commons Attribution License 3.0 (CC BY 3.0), which permits unrestricted use, distribution, and reproduction in any medium, provided the original author and source are credited.

\section{ABSTRACT}

Prostate-specific membrane antigen (PSMA) is a promising target for the diagnosis of and therapy for metastatic castration-resistant prostate cancer ( $m$ CRPC). The aim of this study was to measure overall-survival (OS) in mCRPC patients who received either abiraterone or enzalutamide prior to PSMA therapy. The second aim of this study was to analyse the predictors of OS according to different pre-therapeutic parameters and also the responses to the first cycle of radioligand therapy (RLT) base on PSA level. Patients with MCRPC and a history of therapy with either abiraterone or enzalutamide or both, were included in this study. Different laboratory tests and pre-therapeutic parameters have been included into the analysis. One-hundred patients received a total of 347 cycles of Lu-PSMA (median: three cycles). 69 patients showed a decline in PSA two months after the first cycle, and 38 of those patients showed a PSA decline of $=>50 \%$. The median OS was 60 weeks. In the multivariate analysis, the level of albumin, AST and haemoglobin, existence of liver metastases and a decline of $>14 \%$ in PSA level had a significant impact on overall-survival. The median OS is significantly longer in patients without hepatic involvement, with high levels of albumin and Hb and low levels of AST. A decline in PSA levels of more than $14 \%$ was the most important response parameter with regard to overall survival.

\section{INTRODUCTION}

Prostate-specific membrane antigen (PSMA) is a promising target for the diagnosis and therapy of metastatic castration-resistant prostate cancer (mCRPC) [1-5]. Several studies have demonstrated the safety and low toxicity profile of $\left[{ }^{177} \mathrm{Lu}\right] \mathrm{Lu}-\mathrm{PSMA}-617(\mathrm{Lu}-$ PSMA) for the therapy of mCRPC patients [6-12]. Prolongation of overall survival (OS) is one the most important parameters in the evaluation of efficacy of a therapeutic agent. Although, there are still no prospective studies on the OS of mCRPC patients who have undergone Lu-PSMA therapy, results from the first retrospective studies were very promising. These studies showed a positive effect of Lu-PSMA therapy on OS in patients in advanced stages of mCRPC [13-15]. Abiraterone and enzalutamide are both the approved hormone therapies for mCRPC patients [16-18]. Papers published to date on OS in $\mathrm{mCRPC}$ patients treated with Lu-PSMA therapy included small numbers of patients and inhomogeneous patient groups. The primary aim of this study was to measure OS in mCRPC patients who 
received at least abiraterone or enzalutamide as antitumor therapy prior to radioligand therapy (RLT). The second aim of this study was to analyse the predictive value of different pre-therapeutic parameters and the prostate-specific antigen (PSA) level response to the first cycle on OS.

\section{RESULTS}

\section{Patients}

Between December 2014 and March 2017, 150 patients were treated in our department. Fifty of these patients were excluded from the study, on the basis of the inclusion criteria, for the following reasons: 2 patients had renal cell carcinoma, 23 patients were not treated with either abiraterone or enzalutamide, 10 patients were still under therapy and had undergone less than three cycles of RLT, 3 patients had less than two months of follow-up after the last RLT cycle and 12 patients had incomplete documentation about follow-ups.

In total, 100 patients received a total of 347 cycles of Lu-PSMA (median: three cycles; range: one to eight cycles). Seventy-seven patients (77\%) had a good Eastern Cooperative Oncology Group (ECOG) performance status scores ( 0 or 1$), 22$ patients had an ECOG score of 2 , and one patient had an ECOG of 3. Thirty patients had a Gleason score $\leq 7,61$ had a score $>7$ and the score was unknown in nine patients (Tables 1-3). At the time of analysis, 52 patients $(52 \%)$ were still alive.

\section{Number of cycles}

There were three patients underwent one cycle of therapy, and 18 patients underwent two cycles of therapy. One of the three patients who received one cycle of therapy was the patient who had an ECOG score of 3. This patient with diffuse bone and multiple partially PSMA negative liver metastases died 2.5 months after the first treatment cycle. The other two patients with one cycle of therapy avoided additional treatment cycles and died 16 and 18 weeks after RLT, respectively. Of 18 patients who had two treatment cycles, three showed a near complete response to the first two cycles on the basis of ${ }^{68} \mathrm{Ga}-\mathrm{PSMA}$ PET (positron emission tomography) imaging and a decline in their PSA levels to under $4 \mathrm{ng} / \mathrm{ml}$; therefore, we decided to follow-up on these patients. The remaining 14 patients who received two cycles of treatment experienced a significant rise in PSA levels concomitant with a worsening of their general health condition, particularly with an increase in fatigue, so we decided to end the RLT. Other patients underwent at least three cycles of RLT. In this study, [3, 4, 9, 18] and 2 patients received $[4,5,6,7]$ and 8 cycles of therapy, respectively. The median injected activity per cycle was $6.0 \mathrm{GBq}$.

Sixty-two, 16 and 1 patients received $[3,4]$ and [5] consecutive cycles of treatment at 6- to 8-week intervals.
Twenty-four patients underwent further cycles at a later time because of recurrence, which was identified based on a rise in PSA levels and disease progression that was observed in PSMA PET imaging. All of these 24 patients were patients with favourable response to the first cycle of PSMA therapies according to changes in the PSA levels.

\section{Treatment response to the first cycle}

Sixty-nine patients $(69 \%)$ showed a PSA decline 2 months after the first cycle, 38 (38\%) of which showed a PSA decline of $\geq 50 \%$.

\section{Survival analysis and prognostic factors}

Survival was calculated from the day of the first RLT cycle. The median OS was 60 weeks in all patients, irrespective of response to treatment (95\% CI: 47.3-72.7). The univariate analysis showed that low levels of aspartate transaminase (AST $\leq 24 \mathrm{U} / 1)$, gamma-glutamyl transferase $(\mathrm{GGT} \leq 31 \mathrm{U} / \mathrm{l}), \mathrm{CRP} \leq 16 \mathrm{mg} / \mathrm{l}$, lactate dehydrogenase $(\mathrm{LDH}<225 \mathrm{U} / 1)$ and ALP $\leq 140 \mathrm{U} / 1$; high pre-therapeutic haemoglobin $(\mathrm{Hb} \geq 10.4 \mathrm{~g} / \mathrm{dl})$; high albumin (albumin $\geq$ $38.6 \mathrm{~g} / \mathrm{l})$; lower number of bone metastases; absence of liver metastases; an ECOG status of $0 / 1$; no history of prior blood transfusion; no regular intake of analgesics; any decline in PSA levels and a decline in PSA levels of $\geq 50 \%$ were significant predictors of OS (Table 4 ). Analyzing the percentage of PSA decline after the first cycle determined a PSA decline $\geq 14 \%$ as best cut-off point with a median OS of 88 weeks vs. 29 weeks.

In the multivariate analysis, only albumin, AST and $\mathrm{Hb}$ levels, existence of liver metastases and a PSA decline $\geq 14 \%$ remained significant (Table 4) (Figure 1). The other pre-therapeutic parameters were not significant with regard to OS.

Prior chemotherapy was not a significant predictor of OS. In the current study, 70 patients had been treated previously with chemotherapy; of those, 21 patients also had second-line chemotherapy with cabazitaxel. The patients with prior chemotherapy had a median OS of 57 weeks (90\% CI: 40.2-73.8) compared to 63 weeks $(95 \%$ CI: 49.1-76.9) in patients without chemotherapy ( $p=$ 0.40) (Figure 2A).

Forty-nine patients received only docetaxel; those patients had a median OS of 53 weeks (90\% CI: $34.5-$ 71.5). The median OS in the 21 patients underwent both docetaxel and cabazitaxel had not yet been reached ( $p=$ 0.07) (Figure 2B).

\section{DISCUSSION}

According to several retrospective studies, there is a high response rate to Lu-PSMA therapy [6-9, 19, 20] and a very low probability of high-grade hematotoxicity $[8,12]$ or nephrotoxicity $[8,11,21]$. However, apart from 
Table 1: Blood, renal and hepatic parameters prior to the first cycle of treatment

\begin{tabular}{|c|c|c|c|c|}
\hline Parameter & $\min$ & $\max$ & mean & median \\
\hline \multicolumn{5}{|l|}{ Blood parameters } \\
\hline WBC (G/1) (norm: 3.6-10.5) & 1.52 & 12.2 & 6.1 & 5.7 \\
\hline $\mathrm{Hb}(\mathrm{g} / \mathrm{dl})($ norm: $12.5-17.2)$ & 6.0 & 13.6 & 10.9 & 11.3 \\
\hline Plt (G/1) (norm: 160-370) & 62.0 & 562.0 & 248.0 & 240.0 \\
\hline \multicolumn{5}{|l|}{ Renal parameter } \\
\hline Creatinine (mg/dl) (norm: $0.6-1.3$ ) & 0.38 & 1.9 & 0.9 & 0.9 \\
\hline \multicolumn{5}{|l|}{ Liver function tests } \\
\hline Bilirubin total (mg/dl) (norm: $0.2-1.0)$ & 0.2 & 1.7 & 0.4 & 0.4 \\
\hline ALT (U/l) (norm: < 50) & 7.0 & 423 & 26.1 & 18.0 \\
\hline $\operatorname{AST}(\mathrm{U} / \mathrm{l})($ norm: $<50)$ & 9.0 & 359.0 .0 & 33.8 & 23.0 \\
\hline GGT (U/1) (norm: < 55) & 15.0 & 808.0 & 65.3 & 35.0 \\
\hline Albumin (g/l) (norm: 35-52) & 25.8 & 47.1 & 39.9 & 38.9 \\
\hline
\end{tabular}

${ }^{*}$ Sixteen patients had received a blood transfusion because of grade 3 tumour anaemia between 0 and 300 days prior to the first cycle of Lu-PSMA therapy (median: 17 days).

Abbreviations: ALT, alanine transaminase; AST, aspartate transaminase; GGT, gamma-glutamyl transferase; Hb, haemoglobin; Plt, platelets; WBC, white blood cells

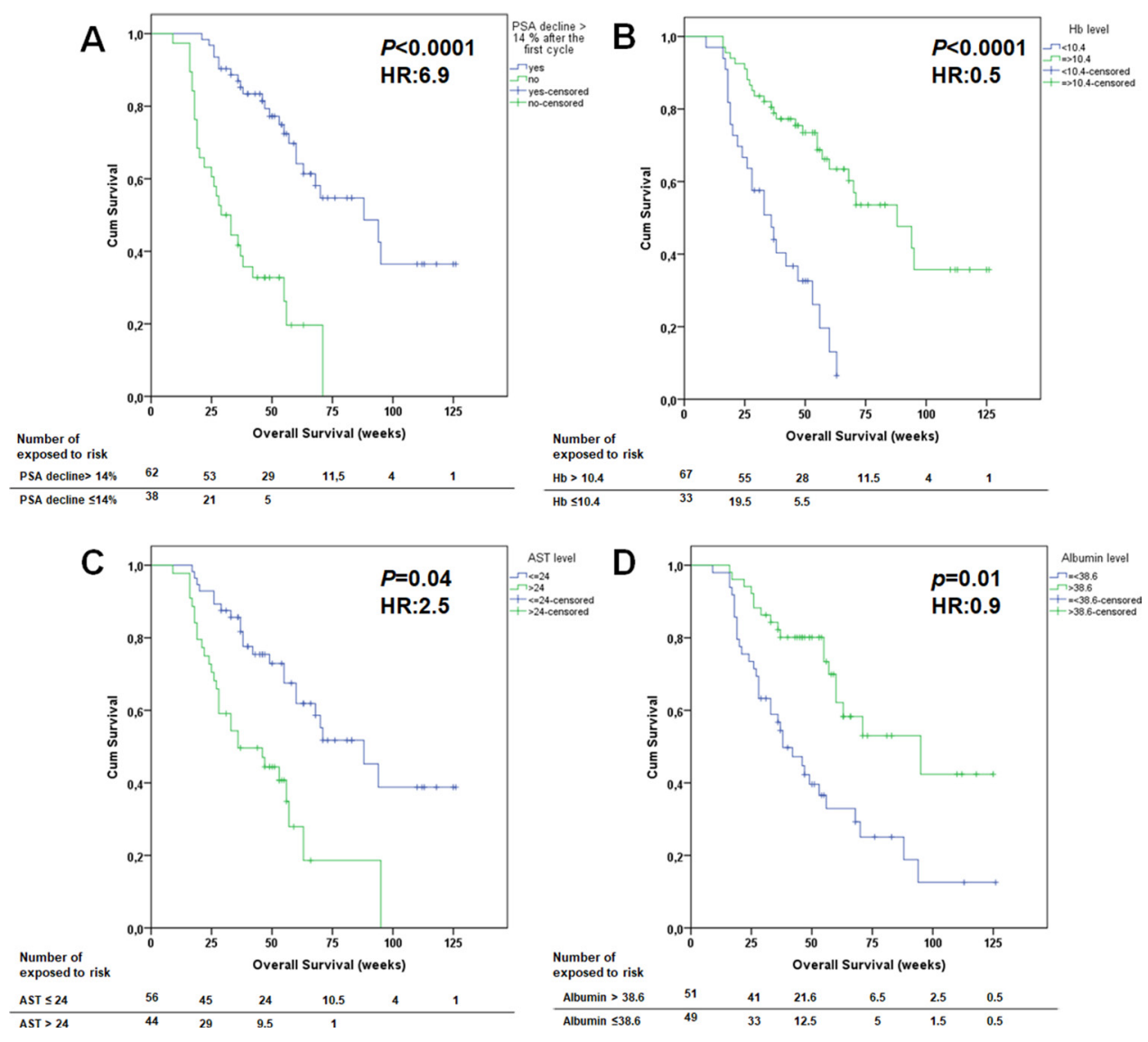

Figure 1: Kaplan-Meier survival curves of prostate cancer patients treated with Lu-PSMA stratified by various prognostic variables in the multivariate analysis. (A) a prostate-specific antigen (PSA) decline more than $14 \%$. (B) $\mathrm{Hb}$ level prior to the first cycle. (C) AST level prior to the first cycle. (D) albumin level prior to the first cycle. 
Table 2: Tumour parameters

\begin{tabular}{lcccc}
\hline \multicolumn{1}{c}{ Parameters } & min & max & mean & median \\
\hline ALP (U/1) (norm: 34-117) & 36 & 1631 & 250 & 133 \\
LDH (U/l) (norm: $<248)$ & 105 & 1875 & 342 & 250 \\
CRP(mg/l) (norm: $<3)$ & 0.2 & 166 & 21.8 & 7 \\
PSA (ng/ml) & 4.73 & 5910 & 520 & 206 \\
\hline
\end{tabular}

Abbreviations: ALP, alkaline phosphatase; CRP, C-reactive protein; LDH, lactate dehydrogenase; PSA, prostate-specific antigen

a good response and a low-toxicity profile, prolongation of overall survival is the most important factor for the evaluation of the efficacy of a new therapeutic agent.

Rahbar et al. [14] compared 28 patients who were treated with a total of 50 cycles of RLT (one to two cycles per patient) with a historical patient cohort treated with the best supportive care prior to the availability of Lu-PSMA [14]. The estimated median OS in their study was 29.4 weeks, which was significantly longer than the OS of 19.7 weeks $(p=0.031)$ that was observed in the historical best supportive care group. Rahbar et al. did not compare the median OS between responders and non-responders, and the majority of patients in this study underwent further cycles of Lu-PSMA therapy after the data had been published.

In a recently published study from our group, 52 patients who received a total of 190 cycles of RLT (three to six cycles per patient) were analysed. In $80.8 \%$ of patients, a decline in PSA levels two months after the first cycle was observed, with $44.2 \%$ showing a PSA decline of $\geq 50 \%$. The median OS was 60 weeks for all patients. The median OS was significantly longer for patients who showed any PSA decline after the first cycle compared to patients without a PSA decline (68 vs 33 weeks). These results were very promising because they showed that Lu-PSMA induces a good response, and in responders it induces a significantly longer OS. In that study, a majority of patients had a history of therapy with abiraterone and/or enzalutamide, and $55.8 \%$ and $44.0 \%$ of patients received chemotherapy and a therapy with Ra-223, respectively.

Bräuer et al. [13] confirmed the results of our published study. They investigated a group of 59 patients who underwent a total of 159 cycles of RLT (median: three cycles). They reported that patients with any decline in PSA levels in response to the first cycle of RLT had a significantly longer median OS (56 weeks) compared to OS of patients with PSA progression (29 weeks). All of the patients in their study had had at least abiraterone or enzalutamide; $80 \%$ and $10 \%$ of the patients had been given chemotherapy and/or therapy with ${ }^{223} \mathrm{Ra}$, respectively.

In both studies $[13,15]$, patients with a decline in PSA levels of $\geq 50 \%$ after the first RLT did not have a significantly longer OS than those with a PSA decline of $<50 \%$. Both studies were limited by a small number of patients, and there was a need to investigate these results in a larger cohort.

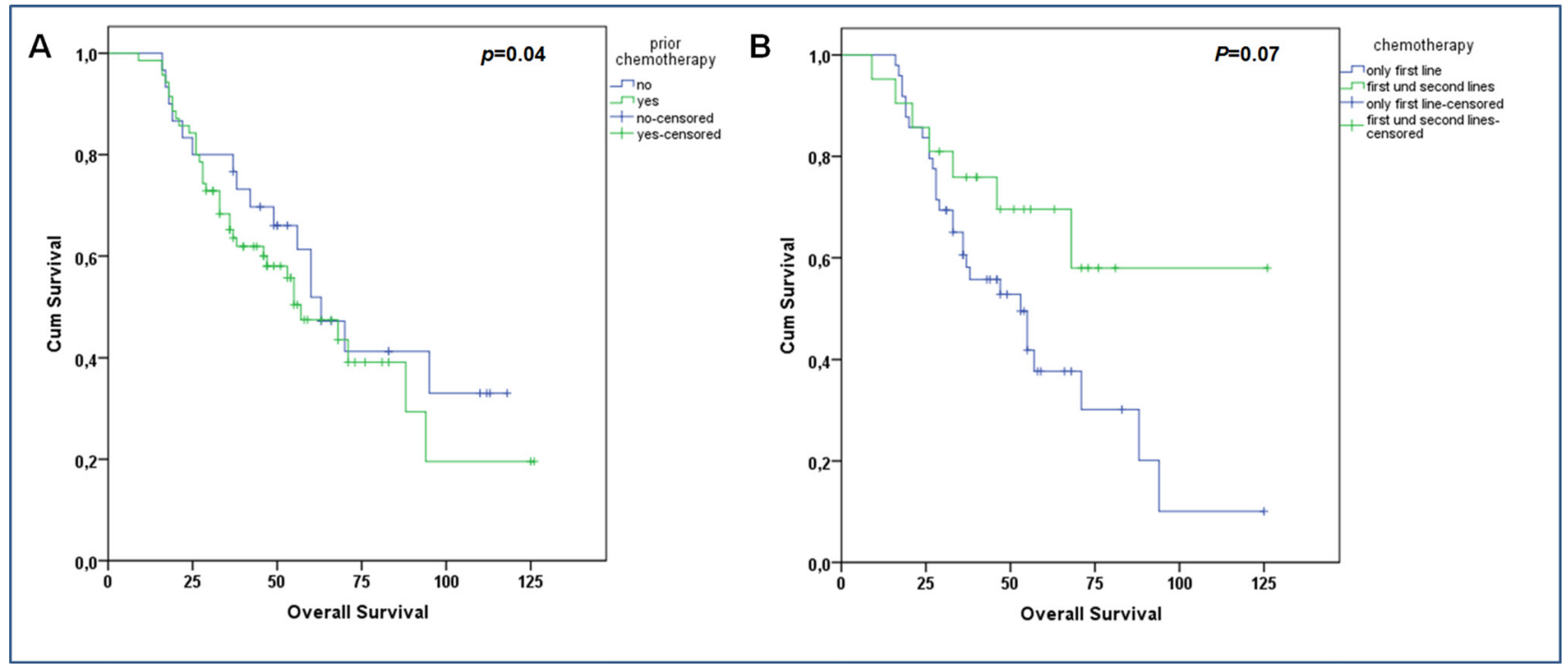

Figure 2: Kaplan-Meier survival curves of patients according to prior chemotherapy. (A) no impact of prior chemotherapy on overall survival. (B) Overall survival considering the number of lines of chemotherapy. Although patients with the history of both docetaxel and cabazitaxel show longer median overall survival, this difference was not significant. 
Table 3: Patient characteristics

\begin{tabular}{|c|c|c|c|c|}
\hline \multicolumn{3}{|c|}{ Gleason score } & \multicolumn{2}{|c|}{ Number of patients } \\
\hline \multicolumn{3}{|l|}{6} & \multicolumn{2}{|r|}{$9(9 \%)$} \\
\hline \multicolumn{3}{|l|}{7} & \multicolumn{2}{|r|}{$21(21 \%)$} \\
\hline \multicolumn{3}{|l|}{8} & \multicolumn{2}{|r|}{$24(24 \%)$} \\
\hline \multicolumn{3}{|l|}{9} & \multicolumn{2}{|r|}{$31(31 \%)$} \\
\hline \multicolumn{3}{|l|}{10} & \multicolumn{2}{|r|}{$6(6 \%)$} \\
\hline \multicolumn{3}{|l|}{ unknown } & \multicolumn{2}{|r|}{$9(9 \%)$} \\
\hline \multicolumn{5}{|c|}{ Prior and ongoing therapies } \\
\hline \multicolumn{2}{|c|}{ Therapy } & History: $n(\%)$ & Ongoing: $n(\%)$ & \\
\hline \multicolumn{2}{|l|}{ Prostatectomy } & $52(52 \%)$ & & \\
\hline \multicolumn{2}{|l|}{ Abiraterone } & $51(51 \%)$ & $21(21 \%)$ & \\
\hline \multicolumn{2}{|l|}{ Enzalutamide } & $33(33 \%)$ & $39(39 \%)$ & \\
\hline \multicolumn{2}{|l|}{ Chemotherapy* $^{*}$} & $70(70 \%)$ & & \\
\hline \multicolumn{2}{|c|}{ Bisphosphonate or RANKL+ inhibitor } & $12(12 \%)$ & $69(69 \%)$ & \\
\hline \multicolumn{2}{|l|}{ Ra-223 } & $36(36 \%)$ & & \\
\hline \multicolumn{2}{|c|}{ Regular need for analgesics! } & & $39(39 \%)$ & \\
\hline \multicolumn{5}{|c|}{ Extent of disease in 100 patients, detected by 68Ga-PSMA-PET/CT } \\
\hline & \multicolumn{2}{|c|}{ Number of patients (\%) } & \multicolumn{2}{|r|}{ Extent } \\
\hline Local recurrence & \multicolumn{2}{|c|}{$40(40 \%)$} & & \\
\hline Bone metastases & \multicolumn{2}{|c|}{$98(98 \%)$} & \multicolumn{2}{|c|}{$\begin{array}{c}<20 \text { metastases in } 29 \text { patients }(29.6 \%) \\
>20 \text { metastases in } 45 \text { patients }(45.9 \%) \\
\text { diffuse metastases in } 24 \text { patients }(24.5 \%)\end{array}$} \\
\hline Lymph node metastases & \multicolumn{2}{|c|}{$78(78 \%)$} & \multicolumn{2}{|c|}{$\begin{array}{c}\text { iliac and abdominal in } 33 \text { patients }(42.3 \%) \\
\text { thoracic in } 9 \text { patients }(11.5 \%) \\
\text { iliac to thoracic in } 36 \text { patients }(46.2 \%) \\
\end{array}$} \\
\hline Liver metastases & \multicolumn{2}{|c|}{$13(13 \%)$} & $\begin{array}{r}\text { singular } \mathrm{r} \\
\text { multiple } \mathrm{m}\end{array}$ & $\begin{array}{l}\text { etastasis in } 1 \text { patient } \\
\text { tastases in } 12 \text { patients }\end{array}$ \\
\hline Lung metastases & & $15 \%)$ & $\begin{array}{l}\text { singular } \mathrm{n} \\
\text { multiple } \mathrm{n}\end{array}$ & $\begin{array}{l}\text { etastasis in } 2 \text { patients } \\
\text { tastases in } 13 \text { patient }\end{array}$ \\
\hline
\end{tabular}

*49 patients had a first-line chemotherapy treatment with docetaxel only, and 21 patients were given both docetaxel and cabazitaxel.

+ Receptor activator of nuclear factor kappa-B ligand.

! Out of 35 patients who have a regular intake of opioids

Currently, abiraterone and enzalutamide are among the first line of therapies used to treat mCRPC [18]. In this study patients who received at least one of these therapies were included. Of the 100 patients included in the current study, $70 \%$ had been given at least a first line chemotherapy with docetaxel. $36 \%$ had been given ${ }^{223} \mathrm{Ra}$ therapy. All of the patients suffered from very advanced disease, with $98 \%$ having bone involvement, $70 \%$ more than 20 lesions up to super scan, and $13 \%$ having hepatic metastases.

Despite their advanced disease and history of various therapies, the median OS was 60 weeks in all patients. The median OS of patients in the study of Bräuer et al. [13] was 32 weeks, which was shorter than the median OS of the patients in our study. This may be because of $48 \%$ of the patients in their study had an ECOG of 2 or 3 compared to only $23 \%$ of the patients in our study. In the current study, patients with an ECOG of 0 or 1 showed significantly longer median OS compared to patients with an ECOG of $2 / 3$ (77 weeks vs. 33 weeks; $p<0.0001$ ). Ferdinandus et al. evaluated the prognostic value of various pretherapeutic parameters on therapy response, based on changes in PSA after the first cycle of RLT [22]. Their multivariate analysis of these parameters showed that patients with a high platelet count or a regular need for analgesics had a significantly worse response to the first RLT cycle, considering any PSA decline after two months. When a PSA decline of $\geq 50 \%$ was considered, patients with a regular need for analgesics showed a worse response in the multivariate analysis; other pre- 
Table 4: Univariate and multivariate analyses of different pre-therapeutic parameters and their impact on overall survival (only the significant parameters are shown)

\begin{tabular}{|c|c|c|c|}
\hline Parameters & $p$-value & $\begin{array}{l}\text { Median OS reported in weeks } \\
(95 \% \mathrm{CI})\end{array}$ & $\begin{array}{l}\text { Multivariate analysis } \\
p \text {-value }\end{array}$ \\
\hline $\begin{array}{l}\text { Number of bone metastases } \\
29 \text { patients } \leq 20 \mathrm{met} \\
45 \text { patients }>20 \mathrm{met} \\
24 \text { patients : super scan or } \\
\text { diffuse bone/bone marrow met }\end{array}$ & 0.02 & $\begin{array}{l}94(60.7-127.3) \\
55(38.8-71.2) \\
37(12.7-61.3)\end{array}$ & $\mathrm{ns}$ \\
\hline $\begin{array}{l}\text { Existence of liver metastases } \\
13 \text { patients: yes } \\
87 \text { patients: no }\end{array}$ & 0.04 & $\begin{array}{l}28(18.6-37.4) \\
60(47.3-72.7)\end{array}$ & $\begin{array}{c}0.02 \\
\text { HR: } 3.2 \text { (95\% CI: } 1.5-7.1)\end{array}$ \\
\hline $\begin{array}{l}\text { ECOG performance status }(0 / 1 \text { vs } 2 / 3) \\
77 \text { patients: } 0-1 \\
23 \text { patients: } 2-3\end{array}$ & $<0.0001$ & $\begin{array}{l}71(43.7-98.3) \\
33(24.7-41.3)\end{array}$ & $\mathrm{ns}$ \\
\hline $\begin{array}{l}\text { Blood transfusion prior to the first cycle } \\
16 \text { patients: yes } \\
84 \text { patients: no }\end{array}$ & 0.04 & $\begin{array}{l}36(28.3-43.7) \\
63(49.5-76.5)\end{array}$ & ns \\
\hline $\begin{array}{l}\text { Albumin (cut-off: } 38.6 \mathrm{~g} / \mathrm{l} \text { ) } \\
49 \text { patients } \leq 38.6 \\
51 \text { patients }>38.6\end{array}$ & 0.0003 & $\begin{array}{c}38(26.0-50.0) \\
95(47.3-142.7)\end{array}$ & $\begin{array}{c}0.01 \\
\text { HR: } 0.9 \text { (95\% CI: } 0.8-0.95)\end{array}$ \\
\hline $\begin{array}{l}\text { AST (cut-off: } 24 \mathrm{U} / 1) \text { ) } \\
56 \text { patients } \leq 24 \\
44 \text { patients }>24\end{array}$ & 0.0002 & $\begin{array}{c}88(61.1-114.9) \\
36(16.8-55.2)\end{array}$ & $\begin{array}{c}0.04 \\
\text { HR: } 2.5 \text { (95\% CI: } 1.3-4.8)\end{array}$ \\
\hline $\begin{array}{l}\text { GGT (cut-off: } 31 \mathrm{U} / \mathrm{l} \text { ) } \\
42 \text { patients } \leq 31 \\
58 \text { patients }>31\end{array}$ & 0.0001 & $\begin{array}{l}88(63.4-112.6) \\
47(31.5-62.5)\end{array}$ & $\mathrm{ns}$ \\
\hline $\begin{array}{l}\text { ALP (cut-off: } 140 \mathrm{U} / \mathrm{l}) \\
52 \text { patients } \leq 140 \\
48 \text { patients }>140\end{array}$ & 0.0003 & $\begin{array}{l}71(45.9-96.0) \\
42(24.0-60.0)\end{array}$ & $\mathrm{ns}$ \\
\hline $\begin{array}{l}\text { ALP (cut-off: } 220 \mathrm{U} / 1) \\
65 \text { patients } \leq 220 \\
35 \text { patients }>220\end{array}$ & 0.019 & $\begin{array}{l}70(56.9-83.1) \\
37(17.7-56.2)\end{array}$ & $\mathrm{ns}$ \\
\hline $\begin{array}{l}\text { LDH (cut-off: } 225 \mathrm{U} / \mathrm{l}) \\
36 \text { patients }<225 \\
64 \text { patients } \geq 225\end{array}$ & $<0.0001$ & $\begin{array}{c}\text { not reached } \\
46(29.6-62.4)\end{array}$ & ns \\
\hline $\begin{array}{l}\mathrm{Hb} \text { (cut-off: } 10.4 \mathrm{~g} / \mathrm{dl} \text { ) } \\
33 \text { patients }<10.4 \\
67 \text { patients } \geq 10.4\end{array}$ & 0.0001 & $\begin{array}{l}36(24.5-47.5) \\
88(60.7-115.3)\end{array}$ & $\begin{array}{c}<0.0001 \\
\text { HR: } 0.5(95 \% \text { CI: } 0.2-0.9)\end{array}$ \\
\hline $\begin{array}{l}\text { CRP (cut-off: } 16 \mathrm{mg} / \mathrm{l}) \\
65 \text { patients } \leq 16 \\
35 \text { patients }>16\end{array}$ & 0.0001 & $\begin{array}{l}71(46.8-95.2) \\
33(25.2-40.8)\end{array}$ & $\mathrm{ns}$ \\
\hline $\begin{array}{l}\text { Regular need for analgesics } \\
39 \text { patients: yes } \\
61 \text { patients: no }\end{array}$ & 0.007 & $\begin{array}{l}36(24.7-47.3) \\
70(56.1-83.9)\end{array}$ & ns \\
\hline $\begin{array}{l}\text { Regular need for opioids } \\
35 \text { patients: yes } \\
65 \text { patients: no }\end{array}$ & 0.0002 & $\begin{array}{l}33(24.9-41.1) \\
88(48.0-127.9)\end{array}$ & $\mathrm{ns}$ \\
\hline $\begin{array}{l}\text { PSA percent change (cut-off: }-14 \% \text { ) } \\
62 \text { patients: decline }>14 \% \\
\text { 38: no PSA decline or decline } \leq 14 \%\end{array}$ & $<0.0001$ & $\begin{array}{l}88(58.3-117.7) \\
29(20.1-37.8)\end{array}$ & $\begin{array}{c}<0.0001 \\
\text { HR: } 6.9(95 \% \text { CI: } 3.6-13.3)\end{array}$ \\
\hline $\begin{array}{l}\text { PSA any decline } \\
69 \text { patients: yes } \\
31 \text { patients: no }\end{array}$ & $<0.0001$ & $\begin{array}{l}71(45.4-96.6) \\
29(20.5-37.5)\end{array}$ & $\mathrm{ns}$ \\
\hline $\begin{array}{l}\text { PSA decline } \geq 50 \% \\
38 \text { patients: yes } \\
62 \text { patients: no }\end{array}$ & 0.009 & $\begin{array}{c}70(39.5-100.5) \\
49(30.2-67.8)\end{array}$ & $\mathrm{ns}$ \\
\hline
\end{tabular}

Abbreviations: ALP, alkaline phosphatase; ALT, alanine transaminase; AST, aspartate transaminase; CRP, C-reactive protein; GGT, gamma-glutamyl transferase; Hb, haemoglobin; HR, hazard ratio; LDH, lactate dehydrogenase; ns, not significant; Plt, platelets; PSA, prostate-specific antigen; WBC, white blood cells. 
therapeutic parameters had no impact on the response to RLT [22].

Based on the study of Ferdinandus et al., we evaluated the impact of numerous pre-therapeutic parameters on OS (Tables 1-3). In the univariate analysis, some of these parameters as well as response to the RLT as measured by PSA were significant (Table 4). In contrast to previously published results from our team and the University Hospital Muenster [13, 15], patients with a decline in PSA levels of $\geq 50 \%$ showed a significantly longer median OS (70 weeks; 95\% CI: 39.5-100.5) than those patients with decline in PSA of $<50 \%$ (49 weeks; 95\% CI: 30.2-67.8).

According to various guidelines and trials, response to a therapy is defined as a $\geq 50 \%$ decline in the PSA levels [16, 17, 23, 24]; however, patients treated with RLT are typically in a very aggressive phase of their disease with a rapidly rising PSA level prior to RLT. Thus, a PSA level that was unchanged two months after the first cycle of RLT could be considered as a response to treatment. In the current study, as with the other two studies mentioned above, patients with any decline in PSA levels showed a significantly longer OS. A decline in PSA of $14 \%$ was a significant cut-off point in both the univariate and the multivariate analysis. Patients with a PSA decline of $>$ $14 \%$ had a median OS of 88 weeks (95\% CI: $58.3-117.7$ ) compared with 29 weeks in patients with PSA decline of $\leq 14 \%$ (95\% CI: $20.1-37.8)(p<0.0001)$.

Thirty-nine patients $(39 \%)$ required analgesics regularly. The need for pain killers was a negative predictor of OS $(p=0.005)$, which was in concordance to the results of Ferdinandus et al. who reported a worse response in these patients [22]. A majority of these patients $(35 / 39)$ took an opioid and had a significantly shorter OS of 33 weeks vs 88 weeks for those not on opioids ( $p=$ 0.0002 ).

The baseline level of PSA was not significant predictor of OS. However, ALP, LDH and CRP (which could be used as tumour-burden parameters) each was a significant predictor of OS in the univariate analysis. In concordance with other studies [13,25], we found that an ALP cut-off level of $220 \mathrm{U} / 1$ was significant in the univariate analysis. In addition, we found that a cut-off level of $140 \mathrm{U} / 1$ was more significant than a cut-off level of $220 \mathrm{U} / 1$ (Table 4$)$.

$\mathrm{The} \mathrm{Hb}$ level was significant in both univariate and multivariate analyses (Table 4). Patients with a $\mathrm{Hb}$ level $\geq$ $10.4 \mathrm{~g} / \mathrm{dl}$ had a longer OS $(p<0.0001)$ than those with $\mathrm{Hb}$ $<10.4 \mathrm{~g} / \mathrm{dl}$. AST, GGT and albumin each was a significant predictor of OS (Table 4).Of these parameters, AST and albumin were also significant in the multivariate analysis. The extent of bone metastases and the existence of liver metastases were significant predictors of OS, with hepatic involvement being significant in the multivariate analysis.

Prior chemotherapy did not have an impact on OS. Of the 70 patients who had received chemotherapy, the median OS in patients with a history of both docetaxel and cabazitaxel treatment was longer than patients treated with docetaxel alone, but the difference was not significant in this study. This may be because the majority of patients with a history of treatment with only docetaxel were not fit enough for therapy with cabazitaxel at the time of the RLT; however, this aspect should be evaluated in a larger cohort of patients.

The median OS in mCRPC patients receiving RLT in advanced stages of disease is 60 weeks. The median OS is significantly longer in patients without hepatic involvement, with high levels of albumin and $\mathrm{Hb}$ and low levels of AST. A decline in PSA levels of more than 14\% measured two months after the first cycle of RLT was the most important response parameter with regard to OS.

\section{MATERIALS AND METHODS}

All patients who underwent Lu-PSMA therapy in our department from Dec 2014 to March 2017 were evaluated for inclusion in this study. Eligible patients were selected according to following inclusion criteria: (1) patients with mCRPC and PSMA positive metastases in the PSMA imaging; (2) patients with a history of therapy with either abiraterone or enzalutamide or both; (3) patients treated with at least three cycles of RLT, or patients with 1-2 cycles of RLT who died before the third cycle, did not receive the third cycle because of significant worsening of their general condition or because of an excellent response to the first or second cycle; (4) patient follow-up of at least two months after the last cycle or the patient died; and (5) complete documentation.

\section{Patients}

In this study, mCRPC patients with distant metastases and progressive disease (determined by PSA levels) were treated with multiple cycles of Lu-PSMA, with a median interval of eight weeks between each cycle (range: six to eight weeks). Patients were followed-up for at least two months after the last cycle. Some of the data from 45 patients who were included in this study had been previously reported $[6-9,12,15,22,26-28]$; however, the current study included a greater number of patients that had all received at least abiraterone or enzalutamide. Additionally, in this paper we have evaluated the predictive factors of OS in a larger cohort of patients. This retrospective study was approved by the hospital's ethics committee. Written informed consent was provided by each patient.

\section{Laboratory tests}

One day prior to each therapy cycle, the following markers were assessed in all patients: hematological and renal status, liver function, PSA, ALP and blood biochemistry. Only the laboratory values obtained shortly 
prior to the first cycle were included in the analysis (Tables 1 and 2).

\section{Parameters evaluated for predictive factors of OS}

All the laboratory tests and parameters shown in tables $1-3$ were included in the analysis. These included the extent of bone metastases, the existence of liver and lymph node metastases, age, the need for pain medication, the ECOG score and prior received cancer-specific therapies.

\section{Treatment}

The PSMA ligand (PSMA-617) was obtained from ABX GmbH (Radeberg, Germany). The preparation of Lu-PSMA has been explained in detail in a previous publication [7]. The treatment solution was administered by slow intravenous injection over 30-60 seconds, followed by $1000 \mathrm{ml}$ of $\mathrm{NaCl}$ or Ringer's solution. All patients were discharged 48 hours after therapy, in accordance with the rules of the Federal Office for Radiation Protection in Germany (BfS).

\section{Tumour response evaluation}

PSA was used as the main marker for response evaluation. Changes in the PSA level were classified as either a decrease of $\geq 50 \%$ or any percentage decrease in PSA. Any increase in PSA was considered to indicate disease progression. According to our previous study [15] a the study by Brauer et al. [13], responders to the first cycle of Lu-PSMA tend to live significantly longer than non-responders. For that reason, only the response to the first treatment cycle was considered as a possible predictive parameter in this study.

\section{Statistical analysis}

The Log-rank test was used to compare survival times between groups of patients defined by qualitative criteria. For continuous variables Maximally Selected Rank Statistics [29] were used to derive optimal cut-off points and a statistical assessment at once. Stepwise Cox regression was used to fit a multivariable risk model to the data.

\section{ACKNOWLEDGMENTS}

We are grateful to the nursing staff of the treatment ward in our department. We give special thanks to our study nurse, Mrs. Ulrike Kuhn-Seifer (Department of Nuclear Medicine Bonn).

\section{CONFLICTS OF INTEREST}

The authors declare that they have no financial or nonfinancial competing interests.

\section{REFERENCES}

1. Afshar-Oromieh A, Hetzheim H, Kratochwil C, Benesova M, Eder M, Neels OC, Eisenhut M, Kubler W, HollandLetz T, Giesel FL, Mier W, Kopka K, Haberkorn U. The Theranostic PSMA Ligand PSMA-617 in the Diagnosis of Prostate Cancer by PET/CT: Biodistribution in Humans, Radiation Dosimetry, and First Evaluation of Tumor Lesions. J Nucl Med. 2015; 56:1697-1705.

2. Afshar-Oromieh A, Malcher A, Eder M, Eisenhut M, Linhart HG, Hadaschik BA, Holland-Letz T, Giesel FL, Kratochwil C, Haufe S, Haberkorn U, Zechmann CM. PET imaging with a [68Ga] gallium-labelled PSMA ligand for the diagnosis of prostate cancer: biodistribution in humans and first evaluation of tumour lesions. Eur J Nucl Med Mol Imaging. 2013; 40:486-495.

3. Rai BP, Baum RP, Patel A, Hughes R, Alonzi R, Lane T, Adshead J, Vasdev N. The Role of Positron Emission Tomography With (68) Gallium (Ga)-Labeled Prostatespecific Membrane Antigen (PSMA) in the Management of Patients With Organ-confined and Locally Advanced Prostate Cancer Prior to Radical Treatment and After Radical Prostatectomy. Urology. 2016; 95:11-15.

4. Ahmadzadehfar H, Azgomi K, Hauser S, Wei X, Yordanova A, Gaertner FC, Kurpig S, Strunk H, Essler M. 68GaPSMA-11 PET as a Gatekeeper for the Treatment of Metastatic Prostate Cancer with 223Ra: Proof of Concept. J Nucl Med. 2017; 58:438-444.

5. Braat A, Ahmadzadehfar H. Lutetium-177 labelled PSMA ligands for the treatment of metastatic castrate-resistant prostate cancer. Tijdschr Nucl Geneesk. 2016; 38:1627-1634.

6. Ahmadzadehfar H, Eppard E, Kurpig S, Fimmers R, Yordanova A, Schlenkhoff CD, Gartner F, Rogenhofer $\mathrm{S}$, Essler M. Therapeutic response and side effects of repeated radioligand therapy with 177Lu-PSMADKFZ-617 of castrate-resistant metastatic prostate cancer. Oncotarget. 2016; 7:12477-12488. https://doi.org/10.18632/ oncotarget. 7245 .

7. Ahmadzadehfar H, Rahbar K, Kurpig S, Bogemann M, Claesener M, Eppard E, Gartner F, Rogenhofer S, Schafers M, Essler M. Early side effects and first results of radioligand therapy with (177) Lu-DKFZ-617 PSMA of castrate-resistant metastatic prostate cancer: a two-centre study. EJNMMI Res. 2015; 5:114.

8. Rahbar K, Ahmadzadehfar H, Kratochwil C, Haberkorn U, Schafers M, Essler M, Baum RP, Kulkarni HR, Schmidt M, Drzezga A, Bartenstein P, Pfestroff A, Luster M, et al. German Multicenter Study Investigating 177Lu-PSMA-617 Radioligand Therapy in Advanced Prostate Cancer Patients. J Nuc Med. 2017; 58:85-90.

9. Rahbar K, Schmidt M, Heinzel A, Eppard E, Bode A, Yordanova A, Claesener M, Ahmadzadehfar H. Response and Tolerability of a Single Dose of 177Lu-PSMA-617 in Patients with Metastatic Castration-Resistant Prostate Cancer: A Multicenter Retrospective Analysis. J Nucl Med. 2016; 57:1334-1338. 
10. Kratochwil C, Giesel FL, Stefanova M, Benesova M, Bronzel M, Afshar-Oromieh A, Mier W, Eder M, Kopka K, Haberkorn U. PSMA-Targeted Radionuclide Therapy of Metastatic Castration-Resistant Prostate Cancer with 177LuLabeled PSMA-617. J Nucl Med. 2016; 57:1170-1176.

11. Yordanova A, Becker A, Eppard E, Kurpig S, Fisang C, Feldmann G, Essler M, Ahmadzadehfar H. The impact of repeated cycles of radioligand therapy using [177Lu] LuPSMA-617 on renal function in patients with hormone refractory metastatic prostate cancer. Eur J Nucl Med Mol Imaging. 2017; 44:1473-1479.

12. Ahmadzadehfar H, Zimbelmann S, Yordanova A, Fimmers R, Kurpig S, Eppard E, Gaertner FC, Wei X, Hauser S, Essler M. Radioligand therapy of metastatic prostate cancer using 177Lu-PSMA-617 after radiation exposure to 223Radichloride. Oncotarget. 2017; 8:55567-55574. https://doi. org/10.18632/oncotarget.15698.

13. Brauer A, Grubert LS, Roll W, Schrader AJ, Schafers M, Bogemann M, Rahbar K. 177Lu-PSMA-617 radioligand therapy and outcome in patients with metastasized castration-resistant prostate cancer. Eur J Nucl Med Mol Imaging. 2017; 44:1663-1670.

14. Rahbar K, Bode A, Weckesser M, Avramovic N, Claesener M, Stegger L, Bogemann M. Radioligand Therapy With 177Lu-PSMA-617 as A Novel Therapeutic Option in Patients With Metastatic Castration Resistant Prostate Cancer. Clin Nucl Med. 2016; 41:522-528.

15. Ahmadzadehfar $\mathrm{H}$, Wegen S, Yordanova A, Fimmers R, Kurpig S, Eppard E, Wei X, Schlenkhoff C, Hauser $\mathrm{S}$, Essler M. Overall survival and response pattern of castration-resistant metastatic prostate cancer to multiple cycles of radioligand therapy using [177Lu] Lu-PSMA-617. Eur J Nucl Med Mol Imaging. 2017; 44:1448-1454.

16. Ryan CJ, Smith MR, Fizazi K, Saad F, Mulders PF, Sternberg CN, Miller K, Logothetis CJ, Shore ND, Small EJ, Carles J, Flaig TW, Taplin ME, et al. Abiraterone acetate plus prednisone versus placebo plus prednisone in chemotherapy-naive men with metastatic castrationresistant prostate cancer (COU-AA-302): final overall survival analysis of a randomised, double-blind, placebocontrolled phase 3 study. Lancet Oncol. 2015; 16:152-160.

17. Scher HI, Fizazi K, Saad F, Taplin ME, Sternberg CN, Miller K, de Wit R, Mulders P, Chi KN, Shore ND, Armstrong AJ, Flaig TW, Flechon A, et al. Increased survival with enzalutamide in prostate cancer after chemotherapy. N Engl J Med. 2012; 367:1187-1197.

18. Cornford P, Bellmunt J, Bolla M, Briers E, De Santis M, Gross T, Henry AM, Joniau S, Lam TB, Mason MD, van der Poel HG, van der Kwast TH, Rouviere O, et al. EAUESTRO-SIOG Guidelines on Prostate Cancer. Part II: Treatment of Relapsing, Metastatic, and Castration-Resistant Prostate Cancer. Eur Urol. 2017; 71:630-642.

19. Fendler WP, Kratochwil C, Ahmadzadehfar H, Rahbar K, Baum RP, Schmidt M, Pfestroff A, Lutzen U, Prasad
V, Heinzel A, Heuschkel M, Ruf J, Bartenstein P, et al. [177Lu-PSMA-617 therapy, dosimetry and follow-up in patients with metastatic castration-resistant prostate cancer]. [Article in German]. Nuklearmedizin. 2016; 55:123-128.

20. Kulkarni HR, Singh A, Schuchardt C, Niepsch K, Sayeg M, Leshch Y, Wester HJ, Baum RP. PSMA-Based Radioligand Therapy for Metastatic Castration-Resistant Prostate Cancer: The Bad Berka Experience Since 2013. J Nucl Med. 2016; 57:97S-104S.

21. Gaertner FC, Halabi K, Ahmadzadehfar H, Kurpig S, Eppard E, Kotsikopoulos C, Liakos N, Bundschuh RA, Strunk H, Essler M. Uptake of PSMA-ligands in normal tissues is dependent on tumor load in patients with prostate cancer. Oncotarget. 2017; 8:55094-55103. https://doi. org/10.18632/oncotarget.19049.

22. Ferdinandus J, Eppard E, Gaertner FC, Kurpig S, Fimmers R, Yordanova A, Hauser S, Feldmann G, Essler M, Ahmadzadehfar H. Predictors of Response to Radioligand Therapy of Metastatic Castrate-Resistant Prostate Cancer with 177Lu-PSMA-617. J Nucl Med. 2017; 58:312-319.

23. Scher HI, Morris MJ, Stadler WM, Higano C, Basch E, Fizazi K, Antonarakis ES, Beer TM, Carducci MA, Chi KN, Corn PG, de Bono JS, Dreicer R, et al. Trial Design and Objectives for Castration-Resistant Prostate Cancer: Updated Recommendations From the Prostate Cancer Clinical Trials Working Group 3. J Clin Oncol. 2016; 34:1402-1418.

24. Petrylak DP, Tangen CM, Hussain MH, Lara PN Jr, Jones JA, Taplin ME, Burch PA, Berry D, Moinpour C, Kohli M, Benson MC, Small EJ, Raghavan D, et al. Docetaxel and estramustine compared with mitoxantrone and prednisone for advanced refractory prostate cancer. N Engl J Med. 2004; 351:1513-1520.

25. Parker C, Nilsson S, Heinrich D, Helle SI, O’Sullivan JM, Fossa SD, Chodacki A, Wiechno P, Logue J, Seke M, Widmark A, Johannessen DC, Hoskin P, et al. Alpha emitter radium-223 and survival in metastatic prostate cancer. N Engl J Med. 2013; 369:213-223.

26. Schlenkhoff CD, Gaertner F, Essler M, Schmidt $M$, Ahmadzadehfar H. Positive Influence of 177Lu PSMA-617 Therapy on Bone Marrow Depression Caused by Metastatic Prostate Cancer. Clin Nucl Med. 2016; 41:478-480.

27. Schlenkhoff CD, Knupfer E, Essler M, Ahmadzadehfar H. Metastatic Prostate Cancer With Restored HormoneResponse After Radioligand Therapy With 177LuPSMA-617. Clin Nucl Med. 2016; 41:572-573.

28. Wei X, Schlenkhoff C, Sopora C, Essler M, Ahmadzadehfar H. Successful Treatment of Hepatic Metastases of Hormone Refractory Prostate Cancer Using Radioligand Therapy With 177Lu-PSMA-617. Clin Nucl Med. 2016; 41:894-895.

29. Lausen B, Schumacher M. Maximally selected rank statistics. Biometrics. 1992; 48:73-85. 